\title{
Analizando un relato de fotografías "únicas": Désiré Charnay (1857-1860)
}

\section{Analyzing a Story of "Unique" Photographs: Désiré Charnay (1857-1860)}

\author{
Fernando Aguayo Hernández \\ (1) https://orcid.org/0000-0002-9726-3012 \\ Instituto de Investigaciones Dr. José María Luis Mora, México \\ faguayo@institutomora.edu.mx
}

Resumen: Este artículo analiza la imagen del explorador Désiré Charnay, es decir, la idea y representación que se tiene sobre dicho explorador, producto del relato escrito por él mismo, el cual ha sido retomado sin analizar las contradicciones que existen en sus aseveraciones. En este estudio se discutirá la originalidad de su obra fotográfica en dos sentidos; por un lado, analizándola en contraposición con la obra del húngaro Pál Rosti y, por el otro, discutiendo los aportes científicos de las fotografías de Charnay, sin dejar de lado el cuestionamiento sobre la supuesta actividad de este "explorador solitario". Así, la hipótesis que se desarrolla es que, como toda imagen, la idea que tenemos de este personaje es producto de la luz emitida en un tiempo y con un propósito específico; al cambiar la distribución de la luz, es posible rescatar a otros personajes, otras intenciones y nuevas interpretaciones a través de explicaciones más críticas y contextualizadas.

Palabras clave: fotografía; exploradores; arqueología; Charnay; Rosti.

cómo CitAR: Aguayo Hernández, F. (2020). Analizando un relato de fotografías "únicas": Désiré Charnay (1857-1860). Secuencia (106), e1713. Dor: https://doi.org/10.18234/secuencia.v0i106.1713

cc Esta obra está protegida bajo una Licencia Creative Commons Atribución-NoComercial 4.0 Internacional. 
Abstract: This article analyzes the image of the explorer Désiré Charnay, in other words, the idea and representation people have of this explorer, due to the story he wrote, which has been read without analyzing the contradictions that exist in his statements. This study will discuss the originality of his photographic work in two respects: on the one hand, analyzing it in contrast to the work of the Hungarian Pál Rosti, and on the other, discussing the scientific contributions of Charnay's photographs, without neglecting to question the alleged activity of this "solitary explorer". Thus, the hypothesis developed is that, like every image, the idea we have of this character is a result of the light emitted at a particular time and for a specific purpose. By changing the distribution of light, it is possible to recover other characters and intentions and new interpretations through more critical, contextualized explanations.

Key words: photography; explorers; archaeology; Charnay; Rosti.

Recibido: 7 de febrero de 2017 Aceptado: 16 de mayo de 2019 Publicado: 9 de diciembre de 2019

\begin{abstract}
$\mathrm{C}$ laude Désiré Charnay fue un viajero francés que desarrolló tres temporadas de exploración en México, entre los años 1857 y 1886, realizando actividades que actualmente se encuadrarían en las disciplinas antropológicas. Si bien este personaje alcanzó fama por su obra escrita, ha sido más reconocido por su labor fotográfica, la cual sirvió como mecanismo para ilustrar los procesos a los que se refirió en sus publicaciones, así como los escritos realizados por otros estudiosos y publicistas.

La mayor parte de lo que se ha escrito hasta el momento sobre el trabajo fotográfico de Charnay se ha realizado a partir de la recuperación de los grupos de imágenes encontrados en los acervos y, sobre todo, a partir de los textos escritos por el propio autor, pues se ha considerado que en ellos existen referencias puntuales al proceso fotográfico, los objetivos de sus exploraciones y los recursos con los que se desarrollaron. Sin embargo, no todo lo escrito sobre este explorador han sido loas, ya que algunos investigadores, a la par de las reseñas sobre sus aportaciones, han realizado también comentarios críticos a partir de análisis puntuales sobre su actuación y su obra, lo que ha permitido matizar los alcances de su labor.
\end{abstract}


El presente artículo busca contribuir a estos nuevos acercamientos y análisis del trabajo de Désiré Charnay ya que, a partir de la construcción crítica de fuentes de investigación, se puede considerar que los textos escritos por Charnay no son un cúmulo de explicaciones sobre el proceso fotográfico, sino un discurso construido con el fin de posesionarse en el ambiente de viajeros con pretensiones científicas.

Uno de los objetivos de este trabajo es realizar un ejercicio comparativo de su producción fotográfica, contextualizándola con otros objetos fotográficos creados en la misma época, con la finalidad de dimensionar su singularidad. Asimismo, se recupera el trabajo arqueológico de gabinete realizado en 1879 por Charles Rau, el cual incorporó fotografías de Charnay, con el fin de valorarlas como documentos apropiados para la investigación.

Otro de los objetivos es analizar cómo se construyó la "imagen" que se tiene de Désiré Charnay: un explorador y fotógrafo solitario que llegó a ser el precursor en la creación de fotografías para el desarrollo de las disciplinas antropológicas, prácticamente sin contar con ninguna clase de recursos. Esto porque esa "imagen" ha contribuido a preservar una forma específica de construir las ciencias sociales hasta nuestros días, pues tras ella se han ocultado procesos sociales en los que participaron una gran diversidad de sujetos. En su conjunto, este texto busca contribuir al análisis crítico de las ideas desarrolladas sobre la fotografía y el surgimiento en el siglo xix de las actividades en torno a las nacientes ciencias del hombre.

\section{CHARNAY Y LOS 1500 KILOS DE EQUIPO}

Désiré Charnay realizó su primer viaje a México en 1857; no fue el primero de nacionalidad francesa que arribó a nuestro país con preocupaciones arqueológicas; sin embargo, se ha considerado el más importante de los que precedieron a la Comisión Científica de México creada en 1864, en el marco de la intervención francesa. Se ha dicho que la relevancia de Charnay reside en la utilización de la fotografía para la investigación, por lo que se le ha considerado parte importante en los antecedentes de la construcción de disciplinas tales como la arqueología o la antropología en México. ${ }^{1}$ No obstante, habría que

\footnotetext{
${ }^{1}$ Como lo señalan diversos especialistas en temas de arqueología mexicana, con Charnay "aparece un importante elemento técnico nuevo: la cámara fotográfica" (Bernal, 1992,
} 
analizar cuidadosamente de dónde surge la supuesta particularidad acerca de las actividades de este explorador. Este texto ofrece algunas hipótesis sobre la producción fotográfica y plantean otras líneas de investigación.

Quienes han recuperado los antecedentes del trabajo fotográfico de Charnay concuerdan en que se inició en la fotografía en París, y consideran que a su llegada a México en 1857 ya era un operador de cámara experimentado; además, son unánimes al expresar su reconocimiento a la calidad de sus registros y en enunciar la gran cantidad de dificultades que enfrentó en la creación de esos documentos fotográficos. Sin embargo, al abordar cómo se llevó a cabo la elaboración de estos objetos, se descarta la evidente presencia de otros participantes en su creación, lo que ha reforzado el discurso que ubica a este personaje como un hombre que creó su obra en la soledad de sus viajes.

Se ha mencionado que nuestro autor siguió los pasos de exploradores que le precedieron, pero poco se ha cuestionado la distancia que Charnay establece con ellos, a partir precisamente del uso de la fotografía. Al momento de su llegada a México, los lugares capturados con su lente no eran territorios ignotos. No se trataba pues de que su travesía fuera inédita, aun cuando su narración así lo quiera hacer ver, sino de rebatir lo ya dicho por otros, principalmente Stephens, a través de testimonios más "fieles" e incuestionables. Esta idea de veracidad, y no tanto su recorrido, es lo que le daría, según el autor, su particularidad. Por ejemplo, acerca de su estancia en Izamal anota que algunas estructuras que se encontraban en el centro mismo de la ciudad habían sido ya mostradas por "Stephens y Catherwood en su álbum litográfico". Pero añade, sin perder oportunidad de señalar el valor de sus fotografías: "Este es el momento de recordar de qué manera se entiende la historia. Tales señores colocaron las figuras mencionadas en un desierto; al pie de la pirámide, se encuentra un tigre enfurecido mientras que los indios salvajes le apuntan con sus flechas. A fuerza de querer conseguir color local, se falsea la historia y se desvía la ciencia" (Charnay, 1994, p. 158).

Para superar esas supuestas falsedades, Charnay ofrecía las bondades de la fotografía. Según su punto de vista, la "indiferencia del público por una civilización tan original" se debía "a las imprecisiones que la velaban a medias”, por eso se propuso generar imágenes que detentaban entonces el pres-

p. 113; Bittencourt y Carrillo, 2014, pp. 117 y 124; Davis, 1981, p. 16; Esmeraldo, 2007; Odena, 1988; Schávelzon, 2003). 
tigio de ser copias fieles de la realidad y con ello demostrar "la exactitud de su trabajo" presentando "a la fotografía como testigo" (Charnay, 1994, p. 29).

Antes de proseguir, es preciso analizar críticamente la imagen que el viajero construyó de sí mismo, la cual ha sido adoptada y reproducida por casi todos los que se refieren a este personaje para analizar la idea de "testimonio", de fidelidad, que incluso hoy se continúa dando a la fotografía como prueba irrefutable de "autenticidad" (Davis, 1981, pp. 104 y 108; Esmeraldo, 2007).

Generalmente se ha reproducido la premisa de que fue un pionero que superó las dificultades técnicas de sus viajes, pues se da relevancia a lo que él mismo menciona en su narración sin cuestionar cómo el autor autogenera su imagen de heroicidad, a través de su relato realizado en primera persona, la cual se ha repetido constantemente desde su origen mismo. De esta forma se ha dicho que "la labor de Désiré Charnay es considerada una proeza, ya que antes los arqueólogos viajaban con un dibujante, quien elaboraba las litografías, sin embargo, Charnay viajaba con su cámara y equipo fotográfico completo, el cual tenía un peso aproximado de 1500 kilos, con los que tenía que atravesar montañas, cruzar ríos e intrincadas selvas" (Los grandes fotógrafos, 2017). Algunos otros autores reafirman la hazaña aumentando a 1800 kilos la carga que debería cargar el sufrido fotógrafo (Bittencourt y Carrillo, 2014, p. 119; Davis, 1981, p. 12; Ochoa, 1994, p. 18; Odena, 1998, p. 615); en tanto que otros la elevan a 8000 kilos (Podgorny, 2008, p. 581).

Se ha escrito que tomó fotografías batallando contra el calor sofocante, la humedad y los enjambres de mosquitos, atravesando montañas y barrancos, mares y bosques tropicales, y en medio de la inseguridad propia de un país en guerra como México (Bittencourt y Carrillo, 2014, p. 118; Davis, 1981, pp. 12-16; Mongne, 2001, p. 18; Odena, 1988, p. 615). Además, "cada negativo tenía que ser preparado justo en el momento de hacer la toma y debía ser procesado por el fotógrafo inmediatamente después, así que todo el equipo, aparatos y medios químicos debían ser transportados en la expedición”. El gran Charnay relataría con lujo de detalles este tipo de experiencias (Odena, 1998, p. 615). Este último comentario nos pone ya en las coordenadas precisas para explicar la fama de la que goza este autor: la forma en que realizó la narración de su primer viaje. Un relato con "fuertes tintes científicos" en los que "puede adivinarse una suerte de alquimia" (Ochoa, 1994, p. 17).

Es decir, la imagen que generalmente se tiene de Charnay como fotógrafo se construyó a partir de la recuperación de lo escrito por él mismo, "con lujo de detalles" en el libro Ciudades y ruinas americanas, publicado en 1863. 
Sin embargo, en sus posteriores textos el tema fue menguando, como se puede ver en América pintoresca de 1884 y es casi inexistente en su obra Viaje a Yucatán, donde únicamente se remite a tres menciones, anotadas tangencialmente (Charnay, 1978, pp. 22, 34 y 43). Es notable la diferencia de contenido en torno a la fotografía con el paso de los años, a pesar de que, de acuerdo con el material que se encuentra en los acervos, la cantidad de fotografías elaboradas en los viajes posteriores es mayor a su primera incursión. Haría falta explicar cuál sería la singularidad del trabajo fotográfico de Charnay con respecto a lo que otros personajes realizaban en esa época, y por qué no es un tema que se replique en sus publicaciones posteriores a 1863.

\section{EL RELATO DE DÉSIRÉ CHARNAY}

Una explicación que se ha dado acerca de esta diferencia en las narraciones es que la disparidad se debe a la madurez del propio personaje (Gallegos, 1999). También es probable que, debido a las críticas que tuvo su actuar en el viaje realizado en 1880, Charnay adoptó un tono más circunspecto en los relatos posteriores a esa fecha. Otras dos posibilidades serían, en primer lugar, que en sus subsecuentes viajes usó técnicas de fotografía diferentes, lo que hizo menos complicado los registros de imágenes, hasta llegar al de 1886 en el que el trabajo carece ya de toda epopeya. La segunda es que, en su primer viaje a México, en contraposición al segundo y tercero, no buscaba realizar registros científicos, sino hacerse de una fama como explorador, por lo que resultaba importante resaltar sus habilidades. En este texto se abordará el tema de lo fotográfico.

Sabrina Esmeraldo afirma que Charnay sistematizó los problemas en su práctica del colodión húmedo en el libro Ciudades y ruinas americanas, los cuales evocan el perfil del trabajo fotográfico que realizaban los primeros exploradores (Esmeraldo, 2007). Los arqueólogos refieren la experiencia de este personaje de la siguiente forma: "Andaban esos anticuarios a través de montes y valles cargando un complicadísimo equipo y frágiles placas de vidrio. Cada foto de entonces -y las hay excelentes- era heroica” (Bernal, 1992, pp. 113-114). Cabe preguntar, ¿hacer fotografía en la época del colodión húmedo era una actividad heroica o Charnay le construyó ese tono y con qué fines?

Como ya vimos, se ha repetido en diversos trabajos que el explorador llegó a México en 1857 con tonelada y media de equipo. No debería extrañar- 
nos que buena parte de ese peso estuviera dedicado a sostener las comodidades del viajero y no únicamente sus instrumentos de trabajo. No tenemos manera de saberlo porque Charnay no anotó las características de los medios con que disponía para emprender su labor; ${ }^{2}$ sin embargo, es necesario señalar que en los primeros 40 años de la fotografía, ni siquiera en los países que se autodefinían como "civilizados", la disponibilidad de productos fotográficos era ilimitada, por lo que "un fotógrafo experimentado" no podía pretender realizar su trabajo en exteriores sin abastecerse de todo lo necesario para realizar con éxito sus registros antes de realizar sus viajes.

Todos los operadores de cámara que hicieron sus registros en exteriores empleando el colodión húmedo debían cargar, además de cámaras y tripiés, con un cuarto oscuro portátil, con químicos suficientes para preparar los negativos en el instante mismo de la toma y con los aditamentos y materiales auxiliares para procesarlos antes de que se secara la emulsión. Esa era la complicación inherente a la técnica del colodión húmedo.

Sin embargo, Désiré Charnay primero nos hace sentir pena porque cargaba el equipo fotográfico a cuestas, y en su texto se queja de que "necesitaba cristales, colodión y agua destilada que no poseía" (Charnay, 1994, pp. 115-116), por lo que podemos suponer que no siempre cargaba con el material necesario y debía echar mano de los materiales locales, los cuales calificó de pésima calidad (Esmeraldo, 2007, p. 86). Lo anterior aun cuando se supondría que él conocía los manuales de la época en los que se indicaba con precisión todo lo que un fotógrafo debería contar para el buen éxito de su trabajo. ${ }^{3}$

Por ello, podemos suponer que buena parte de los contratiempos que el autor cita y que han sido repetidos por sus biógrafos, se debieron a la falta de organización de su expedición. Désiré Charnay no reconoce nunca esta circunstancia y achaca sus problemas a la ausencia de materiales locales, cosa de la que no se debería depender, según los manuales fotográficos que refirió. ${ }^{4}$ En este tenor también imputa sus problemas al clima y a la naturaleza

${ }^{2}$ Otros textos hacen referencia a la lista de materiales con los que, en la misma época, distintos fotógrafos realizaban sus tomas en exteriores (Taft, 1964, p. 309).

${ }^{3}$ Charnay (1994, pp. 145 y 222) cita el escrito por Monckhoven: A popular treatise on photography also a description of, and remarks on, the stereoscope and photographic optics, etc. etc.

${ }^{4}$ Sería muy interesante encontrar otras expediciones fotográficas de la época del colodión húmedo realizadas en exteriores en las que sus protagonistas pudieran fabricar con éxito sus componentes en espacios no urbanizados, incluso de los países europeos. Charnay (1994, p. 145) refiere que un alivio a sus problemas se debió a que un amigo acababa de recibir de Francia algunos de los productos que necesitaba. 
poco amable. Igualmente son responsables de sus contratiempos la población mexicana que no cooperaba con sus proyectos (Charnay, 1994, p. 125) y sus propios ayudantes, los indios que, por curiosidad, se lamenta el francés, "a pesar de mis prohibiciones expresas, no podían retirar sus dedos de los clichés terminados". ${ }^{5}$

Es importante resaltar que la mayoría de las veces Charnay escribió en primera persona las penurias sufridas y los logros obtenidos; por ejemplo, en Chichén Itzá dice: "puse de inmediato manos a la obra, preparé productos para el día siguiente, examiné la cámara oscura, los reveladores y los fijadores" (Charnay, 1994, p. 170). Para hacer la toma de un edificio superando el inconveniente ángulo en contrapicada, comenta: "Como el palacio se levanta sobre una pirámide, debí construir sobre la explanada que le precede un cubo de piedra de doce pies de altura, a fin de establecer mi instrumento al nivel del edificio" (Charnay, 1994, p. 192). Además, pareciera que, en ese ambiente hostil, no solamente luchaba para hacer sus fotografías, sino incluso por su propia subsistencia.

De acuerdo con su narración, podríamos creer que pasó varios meses limpiando el terreno, luego otros tantos construyendo tarimas adecuadas para las tomas ("debí construir un cubo de piedra de doce pies de altura") y algún tiempo diseñando y construyendo su cuarto oscuro. También, que en la soledad de la selva preparaba sus productos con materias primas que seguramente él creaba como por arte de magia. Asimismo, considerando que en condiciones óptimas un aguerrido fotógrafo ejecutaba entre ocho y diez negativos al colodión húmedo por día, y que cada reproducción pudo haberle costado a Charnay entre dos y tres ensayos (Charnay, 1994, p. 191; Esmeraldo, 2007, p. 86), debió invertir un tiempo considerable en correr con los negativos del lugar de la toma al cuarto oscuro, instalado a 89 metros del lugar de exposición (Charnay, 1994, pp. 183 y 192). ¿Lo imaginan ustedes de otra forma?

El relato del viajero es adoptado sin mayores reparos por aquellos que recuperan su obra. ${ }^{6}$ Por ello, podríamos afirmar que el éxito del trabajo fo-

${ }^{5}$ Charnay (1994, pp. 191, 192-193). Charnay se enfrentó al calor que deforma la cámara y el chasis en madera, a la arena, al polvo y a los insectos que se adhieren a la imagen (Odena, 1988 , p. 615; Esmeraldo, 2007, p. 86). Por falta de espacio no se hace referencia aquí a otros autores que escriben sobre diversos temas de la fotografía, en los que se reproducen todas las quejas de Charnay y alaban la heroicidad del personaje.

${ }^{6}$ Actualmente se encuentran en curso algunas investigaciones en torno a la obra de Charnay, las cuales plantean nuevas interpretaciones a través del contraste de lo expuesto por el 
tográfico de Charnay reside, principalmente, en la forma en que él mismo lo describió, lo que ha condicionado la manera en la que se ha recuperado e interpretado su labor. Por ello, es imprescindible hacer un análisis más crítico de nuestras fuentes, lo que incluye no sólo el recurrir a otros vestigios, sino, aún más importante, no pasar por alto la información que el propio Charnay nos legó en sus textos.

En primer lugar, es evidente que, tal como sucede en la realización de otras actividades, en los procesos fotográficos, incluidos los que se desarrollaron bajo la dirección de Charnay, la participación de varios individuos es decisiva. En el caso de nuestro personaje, es importante tener esto en cuenta, ya que aun cuando en la narración del autor se incluyen referencias a sus colaboradores, este disminuye su importancia haciendo énfasis en sus propias hazañas, lo que ha contribuido a que, hasta la fecha, se piense en su producción fotográfica como una obra realizada por una única persona en condiciones extraordinarias. Asomémonos al trabajo en el cuarto oscuro y el entorno de los registros en Uxmal:

Sobre una mesa que me prestaron en la hacienda, instalé mis baños y mis productos. Dos indios tenían por única ocupación la tarea de traerme agua. Otros cuatro debían ayudarme en mis operaciones, sostener un dosel de sábana blanca encima del instrumento, para que el interior del cuarto no se calentara demasiado; tenían que abrirme la puerta del cuarto oscuro y cerrarla herméticamente cuando yo entraba. Otros cuarenta indios fueron ocupados tres días en cortar el monte con el fin de limpiar los monumentos cubiertos de maleza y plantas trepadoras. Antonio formaba mi reserva y no me abandonaba; el sostenía la luz mientras que, sobre mi cabeza, durante el trabajo de revelado, los cuatro primeros indios sostenían igualmente una sábana para impedir que la gravilla de la bóveda cayera sobre la capa de colodión (Charnay, 1994, p. 183).

En este ejemplo, 40 personas trabajan en las locaciones de registro y siete más en el cuarto oscuro, ya que se requería de la participación de un equipo para que la producción fotográfica existiera. Charnay puede ser "li-

francés e información de archivo y otros documentos, como la propia fotografía. Ejemplos de lo anterior son la investigación de Adam Sellen, presentada en el ciclo de conferencias Viajeros e Intelectuales en el Área Maya durante el Siglo XIX, realizado en el Instituto de Investigaciones Filológicas de la UNAM del 27 al 29 de noviembre de 2017 y en Martínez (2018). 
beral" al reconocer la ayuda de otras personas para cargar, limpiar y sostener objetos, pero con el trabajo delicado es más discreto y no otorga esas concesiones. Julieta Martínez (2018, p. 25) señala que, a su llegada a la ciudad de México en 1858, la prensa citadina menciona a Charnay junto a otros dos personajes, Camus y Pinet, como "fotógrafos enviados del gobierno francés". Ella sostiene que pueden ser los dos amigos con los que Charnay (1994, p. 9) salió de Francia, según refiere el propio autor en su texto. En tanto que Olivier Debroise (1989, p. 10) apunta que Louis Goupil era el impresor de las fotografías tomadas por Charnay. Davis (1981, p. 16) también refiere el trabajo que hizo Goupil en el taller fotográfico y que, en septiembre de 1860, Charnay y Louis Goupil escalaron el Popocatépetl para tomar fotografías. Ambas cosas, la existencia de operadores de cámara y ayudantes especializados en el cuarto oscuro, son minimizadas en su texto.

Es por eso por lo que en la imagen (la idea de una persona, la representación que es objeto de culto) que tenemos de este personaje (captada por nuestros sentidos gracias a la luz que recibe y proyecta), deja a otros participantes del trabajo en la sombra, son invisibilizados. Para explicar cómo resolvió el transporte de 1500 kilos de equipo se le presenta como un viajero solitario caminando en terrenos agrestes bajo el peso de su carga. Sin embargo, existen evidencias de que las condiciones fueron diferentes.

Como ya hemos visto, hay testimonios de la participación de un número considerable de personas que hicieron posible los logros de Charnay, desde aquellos que participaron en la elaboración de las fotografías hasta los que fueron utilizados en sinfín de tareas, sobre todo las pesadas. Para poder trasladar el equipo del viajero se utilizaron todo tipo de transportes. En ocasiones, cuando los caballos escaseaban tuvo "la penosa" necesidad de "requisarlos" (Charnay, 1884, p. 379). En otros espacios, como Tumbalá, en Chiapas, el aventurero afirmó que, además de la falta de bestias, los equinos "no pueden franquear los senderos a pico", razón por la cual "en toda la montaña, los indios hacen el oficio de bestias de carga" (Charnay, 1994, p. 229). No solamente puso por escrito este testimonio, sino que publicó en diversas ocasiones la imagen "Pasaje de la cordillera" (véase imagen 1), en la que se presenta otra forma de ver al explorador y suponer que no fue él quien cargó sobre sus hombros los 1500 kilos de equipo, sino los animales previstos para ello y, en su ausencia, la espalda de los pobladores locales, quienes inclusive tuvieron que cargar al propio explorador. 


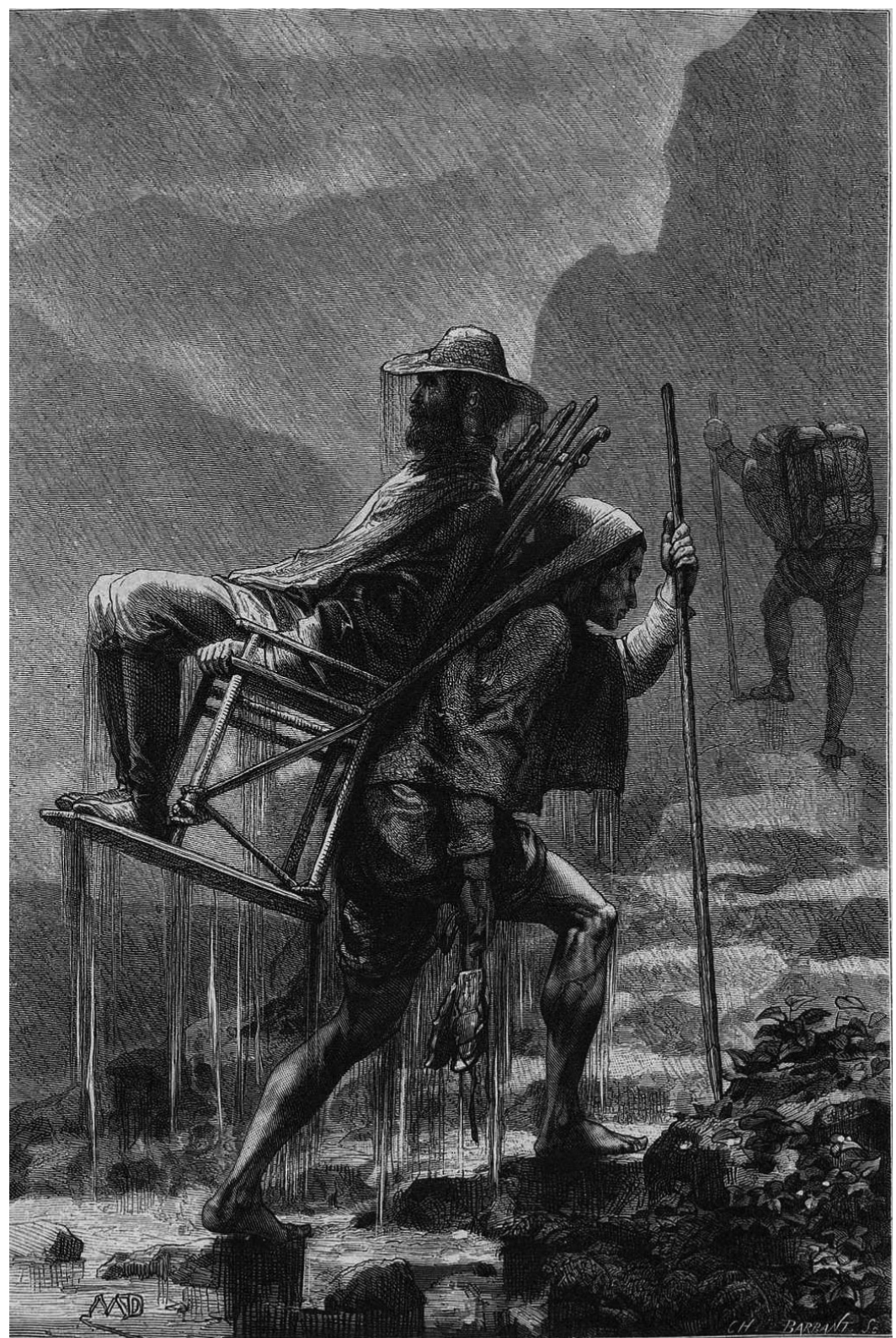

Imagen 1. [Grabado de Ch. Barrant S. (atribuido)]. En Charnay (1885, p. 433). 


\section{EL EQUIPO FOTOGRÁFICO DE CHARNAY}

En esa época, algunos importantes fotógrafos, como William Henry Jackson, no ocultaron que tenían contratados operadores de cámara como parte del componente humano necesario para producir sus fotografías. En su equipo había no solamente cargadores y otros peones que fueron utilizados como "escala humana" en determinadas tomas, sino fotógrafos y personas que preparaban los negativos y hacían trabajos en el cuarto oscuro. Incluso varios autores, al igual que Charnay, lo hicieron en diversas ocasiones (Davis, 1981, p. I), se hicieron retratar en las escenas que los registraron, junto al cuarto oscuro portátil, encima de los vestigios arqueológicos o transportando el equipo fotográfico (Taft, 1964, pp. 296, 305). Es por ello que, en lugar de recibir pasivamente la idea del fotógrafo solitario, debemos analizar la existencia de firmas fotográficas para el análisis de las relaciones sociales.

Más allá de lo escrito por Charnay y lo que recientemente se ha recuperado sobre cómo estaban conformadas las expediciones arqueológicas, existen evidencias gráficas publicadas en textos para ilustrar las hazañas de los exploradores. Por ejemplo, en el grabado "Campement dans la forêt", realizado a partir de una imagen atribuida a Charnay, un fotógrafo registró a otro fotógrafo y a un explorador escribiendo sus notas, mientras que otros miembros de la expedición realizan actividades para el mantenimiento del campamento. En tanto los viajeros trabajan, el único miembro "no occidental" de la imagen aparece plácidamente descansando sobre el tronco de un árbol (Charnay, 1885, p. 367).

Esa es la imagen que se nos ha presentado de casi todos los viajeros como héroes vencedores de "cientos de dificultades físicas, políticas, sociales y naturales. Sus hazañas pretenden ser un faro fiable de veracidad y autenticidad", convirtiendo "su aventura personal en una hazaña de la humanidad civilizada; de la cultura occidental" (Pedro Robles, 2009, p. 210). Se podría plantear como hipótesis que la travesía de Charnay no fue del todo excepcional en comparación con otros fotógrafos de la época, y que su imagen de héroe, tal y como ha llegado hasta nuestros días, es producto de una forma de presentarse, de la elaboración de su pluma acorde a los valores de la época.

Esta imagen ha sido reproducida sin que hasta el momento se haya cuestionado si las adversidades que el personaje relató fueron producto de lo desorganizado de su viaje o meros recursos literarios. Sin embargo, en términos de lo fotográfico, sí existe una singularidad en lo que respecta a su primer 
viaje a nuestro país; esta originalidad consiste en que utilizó negativos de gran tamaño para la realización de las fotografías (Esmeraldo, 2007, p. 86). Davis (1981) es enfático al señalar que fue únicamente entre 1857 y 1860 que utilizó placas tan grandes: una cámara con negativos de $36 \times 45$ centímetros.

De acuerdo con lo publicado en su página, el Museo Quai Branly resguarda la mayoría de los negativos de Charnay realizados en su primer viaje, por ello nos enteramos que en efecto la mayoría de los negativos son de $36 \times 45$ centímetros, pero que también existen negativos con dimensiones más pequeñas de $30 \times 40$ y de $30 \times 42$ centímetros. $^{7}$

Se puede decir que fue el gran tamaño de los negativos lo que originaba verdaderos problemas al usar el colodión húmedo. "Como el nombre de este proceso fotográfico lo indica, estas placas debieron prepararse, exponerse, revelarse y fijarse antes de que el disolvente (éter-alcohol) se evaporara y el aglutinante de colodión se tornara impermeable a los líquidos del procesado" (Valverde, 2012, p. 84). El propio Charnay (1994, pp. 162-163) señala los inconvenientes de la técnica, enfatizando el tamaño del negativo. En tanto que Esmeraldo anota que estas dificultades fueron la razón por la que Charnay no volvió a aventurarse con cámaras fotográficas tan grandes (Esmeraldo, 2007, p. 86).

Antes de proseguir, es necesario hacer un paréntesis para tomar en cuenta la relación entre los negativos y las reproducciones positivas. Si bien los tres productos fotográficos que realizó Désiré Charnay en su primera estancia en México: 1) el Álbum fotográfico mexicano, 2) el álbum de tipos populares y, 3) el álbum de Ciudades y ruinas americanas, fueron realizados con una cámara que empleaba negativos de $36 \times 45$ centímetros; $^{8}$ debemos recordar

${ }^{7}$ Además de la presencia de otra cámara, existen otras dos posibles explicaciones no excluyentes para esta situación: la primera es que esos negativos más pequeños se adaptaran al chasis de la cámara y, la otra, que tiene una confirmación en la ficha del supuesto negativo original de "La Cárcel en Chichén Itzá", es que se trata de negativos copia realizados en fechas posteriores al primer viaje, aunque esto no se indique en la página del Museo Quai Branly. Véase Museo Quai Branly-Jacques Chirac. Colecciones. Désiré Charnay, fotografías. En http://www.quaibranly.fr/fr/explorer-les-collections/base/Work/action/list/?orderby=null \&order=desc\&category=oeuvres\&tx_mqbcollection_explorer\%5Bquery\%5D\%5Btype\%5D=icono \&tx_mqbcollection_explorer\%5Bquery\%5D\%5Bclassification $\% 5 \mathrm{D}=\&$ tx_mqbcollection_explo rer\%5Bquery\%5D\%5Bexemplaire\%5D=\&filters[]=D\%C3\%A9sir\%C3\%A9\%20Charnay\%7C1\%7C

${ }^{8}$ Charnay (1994, p. 162); Davis (1981, p. 142); Valverde (2012, p. 84). Se indica que 43 "de las fotografías del álbum [de Ciudades y ruinas americanas] se produjeron a partir de negativos de vidrio y cinco a partir de negativos de papel" (Bittencourt y Carrillo, 2014, p. 128; Esmeraldo, 2007, p. 86). 
que todos los positivos fotográficos realizados por contacto con esos negativos son de menor tamaño, pues al imprimir las copias positivas se hacía una selección de la toma, sobre todo "para eliminar defectos de manufactura evidentes en las orillas" (Bittencourt y Carrillo, 2014, p. 128).

Para sostener la hipótesis acerca de por qué Charnay utilizó una cámara tan grande, es fundamental esta relación entre negativos y positivos. ${ }^{9}$ También se debe recordar que, de esos trabajos impresos originalmente en papel salado, por lo menos en el caso de dos de los grupos, se hicieron reprografías generando negativos más pequeños, con los que se imprimieron posteriormente copias positivas a la albúmina. Por ejemplo, la fotografía "Puerta lateral de San Francisco" en papel salado mide $30.4 \times 42.7$ centímetros, mientras que la albúmina que se imprimió con el nuevo negativo que reprografió esa imagen, con el título "México. Capilla protestante en San Francisco", mide $12 \times 16.8 \mathrm{~cm}^{10}$

Casi todos los que hacen referencia al tema del tamaño de las impresiones señalan que los positivos se hacían por contacto con los negativos y que la diferencia de tamaños implicaba la reprografía para tener nuevos negativos (Bittencourt y Carrillo, 2014, p. 122). ${ }^{11}$

${ }^{9}$ Negativos de $36 \times 45$ centímetros y positivos más pequeños. A modo de ejemplos, diremos que la fotografía más grande de la llamada "La vista de la ciudad de México", realizada con cinco tomas independientes que al unirse crean el panorama de la ciudad, mide $41 \times 29.9$ centímetros. Distrito Federal. Varilla OYBDF02-780-OYB-725. Secretaría de Agricultura, Ganadería, Desarrollo Rural, Pesca y Alimentación, Mapoteca Manuel Orozco y Berra, México. Mientras que del álbum de 46 láminas con 48 fotografías denominado Ciudades y ruinas americanas, la fotografía "La cárcel en Chichén Itzá" mide $42.5 \times 33.5$ centímetros. Monumentos arqueológicos S.A.G., L3-A3-5, 12932. Secretaría de Agricultura, Ganadería, Desarrollo Rural, Pesca y Alimentación, Mapoteca Manuel Orozco y Berra, México.

10 "Puerta lateral de San Francisco", Álbum Fotográfico Mexicano. CMICH13. Fundación Cultural Televisa e IIE-UNAM, México. Como ejemplo de esta práctica consistente tenemos que la fotografía de la Mapoteca Orozco y Berra "La piedra de la cruz en Palenque", la cual mide $40.2 \times 25.3$ centímetros, y la pieza "La piedra de la cruz Palenque" que mide únicamente $22.6 \times 14.9$ centímetros. Monumentos arqueológicos S.A.G., L3-A3-5, 12945. Secretaría de Agricultura, Ganadería, Desarrollo Rural, Pesca y Alimentación, Mapoteca Manuel Orozco y Berra, México; y número de inventario 426294. Fototeca Nacional, México. Tema ya abordado por Casanova (2005, p. 22).

${ }^{11}$ Aunque existen otros puntos de vista. Al referir el menor tamaño de la "versión nacional" de Ciudades y ruinas, Rodríguez (2007) comenta que ya otros han señalado los procesos de reprografía, pero señala: "aunque también pudo invertir la lente de la ampliadora reduciendo de esta manera el formato de la imagen” (p. 22). Sin tomar en cuenta los testimonios de la época acerca de la dificultad de ese proceso dada la inexistencia de fuentes de luz constantes. 
Las dificultades de trabajar con placas de gran tamaño se pueden medir en los resultados. Meses de trabajo y decenas de tomas produjeron apenas medio centenar de fotografías, algunas de los cuales pudieron ser publicables en el álbum Ciudades y ruinas (Jazzán-Dayán, 2017, p. 64) Compárese ese extraordinario esfuerzo con el comentario que le merece a Charnay el trabajo en la misma zona poco más de 20 años después, utilizando otra técnica y otro tamaño de negativos: "Como viajo con mi aparato fotográfico provisto siempre de placas secas, apenas tuve necesidad de media hora para sacar la vista del cenote" (Charnay, 1978, p. 22).

Si era tal la dificultad, ¿por qué Charnay utilizó ese tipo de negativos en 1857-1860? Existían opciones para escoger el tipo de cámara y el tamaño de negativos. La mayoría de los fotógrafos de la época sabía que lo más sensato era hacerlo con equipo que se pudiera transportar con menos problemas. Con mayor razón debía predecirlo alguien que proyectaba realizar un trabajo de registro en zonas de difícil acceso. Porque, debemos recordar, la propuesta que hizo al Ministerio de Instrucción Pública francés en 1857 consistía en un proyecto mucho más ambicioso que las fotografías de México, pues pensaba realizar una travesía alrededor del mundo, una especie de Tour du Monde fotográfico, lo cual generó el interés del Ministerio (Mongne, 2001, pp. 14 y 19). ¿Por qué Charnay decidió hacerlo con grandes placas que implicaba complejas operaciones de traslado y sensibilización de los materiales?

Se presentan aquí tres hipótesis que no son excluyentes. La primera es que, si desde el principio en verdad pensó hacer fotografías de "gran formato" para el ambicioso proyecto científico, sin que hubiera una correcta planeación al tamaño de esas pretensiones. Una segunda hipótesis, es que, contrario a lo escrito y declarado por Charnay, el explorador no buscaba tener testimonios de lo explorado, sino que planeó crear imágenes fotográficas de gran formato para estremecer a quienes las vieran y por ese medio construirse un prestigio como explorador. Y la tercera hipótesis es que adoptó ese tamaño de placas para emular un trabajo realizado por el húngaro Pál Rosti en México en 1857, apenas unos meses antes de la llegada de Charnay.

\section{PÁL ROSTI EN MÉXICO}

Desde los inicios de la fotografía, la importancia de mostrar evidencias "fidedignas" de las exploraciones arqueológicas residía en el nuevo medio en sí, 
debido a que, como el propio Charnay señala, las fotografías no son creaciones de la imaginación de sus autores, sino "testigos" fieles de la realidad. En términos contemporáneos se dice que son registros indiciales de un referente, huellas fisicoquímicas que reflejan procesos concretos en un instante preciso. Desde la creación del medio, la importancia de la fotografía consistía en generar imágenes que fueran reflejo de lo que encuadraba la máquina, "un lápiz de la naturaleza", pues era "la luz la que pintaba los objetos en el fondo de la cámara" y no la subjetividad de un artista. Si bien es importante el tamaño de las placas, pues, de manera general, a mayor tamaño más información, es el proceso fotográfico en sí el que cumplía con el papel de crear imágenes fieles... de la realidad.

Otra cosa es el impacto visual que generan las impresiones fotográficas en gran formato. Incluso hoy día, en este mundo con millones de imágenes, las grandes fotografías creadas por diversos exploradores (en el caso del México decimonónico: Pál Rosti, Désiré Charnay y William Henry Jackson) resultan impresionantes.

No se han encontrado vestigios del equipo con el que los tres "fotógrafos enviados del gobierno francés" Charnay, Camus y Pinet planearon hacer su viaje alrededor del mundo, para afirmar si en verdad se lanzaron a esa empresa sin los recursos fotográficos necesarios. Antes de expresar una hipótesis sobre el particular se hace necesario recobrar el trabajo fotográfico desarrollado en México en el año 1857 por el húngaro Pál Rosti, ya que él y Désiré Charnay estuvieron viviendo en la misma época en Nueva Orleans, aprendieron el trabajo fotográfico en París en los mismos años y ambos coincidieron en México para hacer fotografías (Jancsó, 2013, pp. 78-80).

Recuperemos algunos datos del trabajo fotográfico de Pál Rosti. Según sus biógrafos, con el dominio de la práctica fotográfica, en 1856 Rosti dijo que emprendería desde París un gran viaje, al "calco de la obra del gran viajero alemán Alexander Humboldt", expresando que la fotografía era el "medio más eficaz para la divulgación de los conocimientos geográficos, las características especiales de las distintas regiones, su flora, ruinas, edificios y ciudades mediante imágenes fieles de los distintos paisajes y el clima" (Jancsó, 2013, p. 80) Así, partió hacia América y elaboró registros fotográficos en Cuba y Venezuela, hasta su arribo a México en julio de 1857, donde durante meses realizó su trabajo fotográfico, el cual probablemente estaba bastante avanzado cuando 
en diciembre de ese año llegó Désiré Charnay a Veracruz, coincidiendo ambos personajes en la capital del país por varios meses. ${ }^{12}$

Hace años Oliver Debroise (1994, pp. 68-69) y Rosa Casanova (2005, p. 12) compararon las imágenes de estos dos fotógrafos, destacando las características de cada uno. ${ }^{13}$ Lo que toca a este texto es mencionar un paralelismo mayor entre las estancias y actividades de ambos personajes, pues lo más sorprendente es que el tamaño de las placas que utilizó Charnay entre 1858 y 1860 son idénticas a las que antes ya había utilizado Pál Rosti.

A partir de una observación de los positivos de papel salado de Rosti, en los que no son perceptibles las huellas que deja el uso de papel como negativo, ${ }^{14}$ se puede lanzar la hipótesis de que usó, como dicen sus biógrafos, "la técnica más moderna de la época", es decir, negativos de vidrio con emulsión de colodión. ${ }^{15}$ El tamaño de uno de los positivos que se encuentran en México es de $34 \times 41$ (Jazzán-Dayán, 2017, pp. 32 y 72) ${ }^{16}$ tamaño similar a los de Charnay, por ejemplo "La cárcel en Chichén Itzá" que mide 42.5 × 33.5 centímetros. Empero, existe un elemento de lo más inquietante, pues resulta que, después del trabajo realizado en América, "no se conoce ninguna otra fotografía de Rosti". Sus biógrafos apuntan que eso se debe probablemente a la pérdida de su posterior trabajo fotográfico, pero cabría preguntarse ¿no se habrá desprendido de su equipo antes de salir de México?, y en caso de que eso sucediera, ¿quién fue el beneficiario de ese material?

${ }^{12}$ En 1859, ya en Europa, Rosti imprimió por lo menos cuatro álbumes fotográficos sobre América, exponiendo sus 47 piezas en papel salado (entre ellas 32 de México) en los siguientes meses, en los que provocó las elogiosas expresiones de los académicos (Jancsó, 2013, pp. 78-80).

${ }^{13}$ La comparación que se hizo entre ambos autores fue sobre los temas (arquitectura colonial, instalaciones industriales y las arqueológicas, etc.), los recursos formales y la composición de las imágenes; lo que llevó a Debroise a concluir que Rosti evitaba el pintoresquismo y su serie, aunque menor a la de Charnay "revela un punto de vista más moderno y un rango temático más amplio" (Debroise, 1994, p. 69). No emitieron opiniones acerca de los objetos fotográficos porque las afirmaciones acerca de las imágenes de Rosti se hicieron a partir de reproducciones impresas a fines del siglo $\mathrm{xx}$ y no con la consulta de los objetos fotográficos.

${ }^{14}$ Agradezco a las restauradoras perito de la Fototeca Nacional, Berenice Valencia y Daniela Carreón, compartir conmigo sus conocimientos y la información obtenida, resultado de la consulta directa de los materiales en el acervo de Budapest.

${ }^{15}$ Jancsó confunde el proceso fotográfico utilizado por Rosti, pues afirma que sus positivos son albúminas y llega a especular que para las tomas fotográficas "utilizó el proceso del papel encerado inventado por Le Grey" (Jancsó, 2013, p. 78).

${ }^{16}$ Las fotografías que se encuentran en Budapest, véase en: http://opac3.mnm.mon guz.hu/en_GB/online-collection/-/results/540312e5-42be-46f8-8183-5da31d403d55/solr\#display Result 
En tanto se resuelven esos interrogantes, queda la afirmación de quienes recuperan el trabajo del húngaro que sobrevive sin las pretensiones de lo realizado por Charnay: "las imágenes tomadas por Rosti son únicas y de muy alto valor: en ninguno de los tres países [Cuba, Venezuela y México] se habían tomado antes imágenes semejantes con meros objetivos científicos y descriptivos" (Jancsó, 2013, p. 78).

Si la producción de Charnay no era diferente a la que hizo Rosti, ${ }^{17}$ ipor qué se le ha puesto tanta atención a la obra del francés? Además de la longevidad de uno, su pertenencia a una potencia imperial y otros factores más, una posible explicación reside en la difusión de la obra escrita del primero y de la forma que Charnay escribió de sí mismo.

\section{LAS FOTOGRAFÍAS “CIENTÍFICAS”}

En cuanto a que el trabajo fotográfico de Charnay tuviera una orientación científica, ya Debroise (1994, p. 78) había señalado que estos fotógrafos "no buscan tanto la precisión como el efecto, la espectacularidad". Por esta razón es que realizó la producción de objetos fotográficos de grandes dimensiones con el fin de impresionar a los interesados en estos temas y no documentos propios para la investigación de gabinete.

Aunque más allá de los propósitos, se puede avanzar en los medios empleados. Para hacerlo se proponen dos temas que estuvieron presentes en la discusión académica acerca de la investigación arqueológica. La primera es la preocupación expresada por exploradores y elites académicas acerca de la destrucción y deterioro de los espacios arqueológicos; la segunda se refiere a las implicaciones de los procesos fotográficos para la preservación del material que supuestamente se quiere rescatar.

A mediados del siglo XIX, cuando diversos sectores se refirieron a las antigüedades que se encontraban abandonadas en diferentes rincones del país, los comentarios a la pervivencia de estos objetos señalaban que las an-

${ }^{17}$ En términos temáticos, la diferencia entre Charnay y Rosti es que el francés realizó en su primer viaje un álbum de tipos populares. En sus publicaciones posteriores, Charnay incorporó fotografías de tipos populares e indígenas realizadas por otros fotógrafos como Cruces y Campa, Huertas y Cía. y Teoberto Maler (Charnay, 1884, pp. 272, 273 y 356; Charnay, 1885, pp. 31, 33, 35, 77, 233 y 441). Estas fotografías casi siempre se han atribuido a Charnay por la simple razón de que aparecen en sus publicaciones. 
tigüedades subsistían pese a los intentos explícitos de los conquistadores españoles por destruirlos y pese al paso de tres siglos y de las condiciones naturales en los que se encontraban. Con la llegada de exploradores de diverso tipo, sus crónicas describieron a sus competidores como destructores de los espacios y saqueadores de objetos. Se hizo común que quienes llegaban a un sitio ya descrito por sus predecesores, denunciaban en distintos tonos la "desaparición" de objetos y hasta edificios.

Se ha justificado que esto sucedió porque los exploradores necesitaban llevarse a su país de origen evidencias de lo que relataban. Recientemente se ha recuperado el problema de la arqueología del siglo xIX consistente en "la transformación de las ruinas de la antigüedad americana en evidencia científica", señalando que tuvo dos soluciones generales. Por un lado, llevarse a su país los vestigios, "fragmentar las estelas, recortar los muros y mutilar las estatuas aparecían como alternativas posibles siempre que se contara con los recursos para pagar el trabajo de los peones y moverlas hasta un centro poblado, salvando los impedimentos ligados a la infraestructura caminera" (Podgorny, 2008, pp. 578 y 581). Por el otro, se trataba de hacer representaciones de las cosas que fueran aceptadas como reflejos fieles de las antigüedades. En muchas ocasiones, ambas opciones generaron destrucción.

En su segunda exploración del volcán Popocatépetl, Charnay llamó ladrones y "tunantes" a los que se habían apropiado de lo que consideraba "su" cementerio prehispánico (Charnay, 1884, pp. 283-284) pero deslizó un delicado comentario acerca de la colosal figura de Izamal descrita y dibujada por Stephens y Catherwood en 1841. Para 1881 esa escultura ya estaba "desaparecida", como consecuencia de los trabajos realizados para la elaboración de los grabados que los hicieron mundialmente famosos (Catherwood, 1978, lámina xxv; Charnay, 1884, p. 376).

El actuar de Charnay no fue diferente. Más allá de las pérdidas ocasionadas por sus labores de extracción y exportación de piezas, la creación de sus fotografías también propició la pérdida de piezas y estructuras que hoy sobreviven solamente en imagen, debido a las prácticas que tenía para la obtención de sus fotografías. Dice este aventurero sobre su proceder en el registro de una fachada y galería: "traté de limpiarlas y de frotar los pilares con el fin de darles un color más fotogénico, pero sin resultados; estuve, además obligado a limpiar todos los objetos que quise fotografiar" (Charnay, 1994, p. 221). Oliver Debroise apunta algunas consecuencias de este proceder. Esta operación realizada en Palenque "provocó la posterior caída de la Torre del 
Palacio. Asimismo, movió algunas de las estelas labradas para fotografiarlas en mejores condiciones de luz: al permanecer a la intemperie, el dibujo se perdió y sólo se conserva en estas imágenes incompletas" (Debroise, 1989, pp. 8-9) En tanto que en Izamal, Charnay hace las fotografías de la cabeza monumental de estuco de cuatro metros de alto, dicha pieza, después de sobrevivir siglos, acabó destruida por las lluvias, después del tratamiento y las labores del fotógrafo. No queda claro si es falta absoluta de autocrítica, o la necesidad que tenía de continuar con el guion de su actuar, pero en 1886 escribe al constatar los desplomes y derrumbes en las construcciones: "El aspecto de esta pirámide ha cambiado mucho desde mi última expedición ¡Cuánta mudanza en tan pocos años!" Señalando a los que considera evidentes culpables de la destrucción: los habitantes de la ciudad (Charnay, 1978, p. 12).

La destrucción de espacios y objetos arqueológicos también se puede documentar para el caso de Palenque. A pesar de los destrozos realizados antes de su llegada, Luciano Castañeda había registrado en 1808 completo y en su lugar el llamado Tablero de la Cruz de Palenque (Farcy, 1927, p. 488). Luego, en 1832, el tablero ya había sido fragmentado en tres. La parte izquierda fue la única que permaneció en su sitio, la de la derecha fue trasladada a Estados Unidos pasando a formar parte del Smithsonian Institute en 1858, en tanto que la parte central también había sido desprendida, pero se encontraba arrumbada en el suelo (Rau, 1882, pp. 154-155).

El tema se menciona aquí para abordar la cuestión de la tan mencionada contribución científica de la fotografía realizada por Charnay. Irina Podgorny (2008) ha planteado el tema de los distintos mecanismos para intentar resolver "un problema de la arqueología del siglo xIx: la transformación de las ruinas de la antigüedad americana en evidencia científica", citando a un personaje que, "en 1904, expresaba que la finalidad de la arqueología era producir 'antigüedades portátiles', es decir planos, fotografías y dibujos para referir los objetos a su lugar de origen" (p. 579). Como se ha señalado, la importancia de las fotografías de Charnay, de estas representaciones de los objetos, radica precisamente en sus aportaciones a las investigaciones científicas.

Sobre este tema resulta que quienes han analizado las fotografías de Charnay no han abordado su contribución al avance de los conocimientos sobre las culturas que registraron. Falta, por ejemplo, investigación acerca de la óptica usada por las cámaras fotográficas y sus efectos en cómo se reproducen los referentes que registraban. Quienes han mencionado que el equipo usado por el explorador modificaba la perspectiva de los monumentos (Bittencourt 
y Carrillo, 2014, pp. 125-126), alabando las virtudes "artísticas" del resultado, niegan que ese fuera el propósito, pues se persiste en repetir el objetivo científico que perseguía, por eso se recupera una investigación de época en la que se usaron las fotografías del explorador.

En el año de 1879, Charles Rau realizó una investigación sobre la sección del llamado Tablero de la Cruz que se encontraba en el Smithsonian, para lo cual recopiló los trabajos escritos y las imágenes publicadas, entre ellas una fotografía ejecutada por Charnay de la sección central. Resulta interesante que en esa recuperación también salieron a relucir las opiniones que cada nuevo explorador tenía de su antecesor en lo referente a las imágenes y su posibilidad para la investigación arqueológica. De esta forma, Stephens señaló que los dibujos de Catherwood eran "más correctos en proporción, diseño y sombras que los de Dupaix, y que suministran más exacto material para especulación y estudio". Mientras que respecto a los dibujos de Waldeck se indicaba que el artista había mejorado las figuras originales, por lo que poco servían a la arqueología. ${ }^{18}$

Lo más interesante es que Charles Rau realizó un trabajo de gabinete teniendo todas las imágenes del tablero, es decir, las realizadas por Ricardo Almendáriz y Luciano Castañeda (bajo la dirección de Antonio del Río y Guillermo Dupaix, respectivamente), las de Waldeck y Catherwood, así como la fotografía de Charnay. Asimismo, Rau había obtenido copias fotográficas de la sección del tablero que se encontraba en el Smithsonian. Con todo ese material en su escritorio formaliza varias aseveraciones, la más general es acerca de la diferencia entre dibujo y fotografía, considerando que "el dibujante, por más hábil que sea, no tiene la precisión del aparato fotográfico". Y ya refiriéndose al Tablero de la Cruz sentencia: "La fotografía de la losa de en medio hecha por Charnay era indudablemente la más semejante al original" (Rau, 1882, p. 161).

Era la más semejante, pero tenía evidentes problemas para la investigación, por ello Rau tuvo que seguir trabajando con todas las representaciones imagéticas para realizar su trabajo. Esta situación no era de lo más reconfortante para los usuarios de la fotografía. Después de los entusiastas inicios de la aplicación de este medio como herramienta de arquitectos y arqueólogos,

${ }_{18}$ Waldeck, "tan buen dibujante como mal arqueólogo" (Farcy, 1927, p. 492). "Aunque el mérito de estos dibujos es digno del más alto aprecio, despiertan en el ánimo del observador algunas dudas sobre su absoluta semejanza con los objetos que representan” (Rau, 1882, p. 143). 
varios de sus iniciales promotores expresaron las limitaciones de la fotografía y su inferioridad frente al dibujo (Scharf, 2001, p. 105). Particularmente Waldeck escribió un texto con este contenido, referido específicamente a las fotografías de Charnay, tomando como ejemplo precisamente la parte central del Tablero de la Cruz, realizando una reflexión general acerca del medio. ${ }^{19}$

Rau reconoció que la fotografía del tablero de la Cruz tenía problemas para usarla en su investigación. No era clara y se encontraba desvanecida, por lo que las figuras representadas eran sumamente difíciles de distinguir (Rau, 1882, pp. 161-162). Resulta sintomático que cuando Charles Rau trata de justificar a Charnay, cite el texto de Ciudades y ruinas en donde el francés refiere los problemas que tuvo para la realización de las fotografías en Palenque. Además de que sean justo esas condiciones de la realización de las imágenes, las que Frédéric Waldeck señala como criticables para una investigación seria.

Exagerando para darle color a su texto, Waldeck afirmó que "la cantidad de dificultades y peligros no le habían permitido al Sr. Charnay quedarse más de veinticuatro horas, por eso sus fotografías parecían haber sido tomadas de pasada. Otros exploradores no retrocedieron ante estos obstáculos" y remata señalando el tiempo que estuvieron en Palenque él y otros viajeros, "por mi cuenta, no me he quedado ahí menos de dos años". ${ }^{20}$ Es decir, la investigación arqueológica y la manufactura de representaciones adecuadas de los objetos requería organizar expediciones que contaran con tiempo suficiente para su realización satisfactoria. También se requería de equipo fotográfico que generara imágenes apropiadas de las antigüedades. Por el contrario, para hacer fotografías "artísticas" de gran formato, no había necesidad más que de unos cuantos días y muchos indios que limpiaran el terreno.

${ }^{19}$ Apunta Waldeck: La ventaja de la aplicación de la fotografía a la arqueología residía en la velocidad con la que se obtienen las impresiones fotográficas y su perfecta precisión, pero siempre será inferior en la fotografía comparada con otras artes gráficas, porque es impropia para reproducir los colores y los detalles. F. de Waldeck, Les antiquités mexicaines et la photographie. Le Trait D'Union, 19 de abril de 1862, pp. 3-4. Debroise (1994, p. 80) refiere este texto de Waldeck y Esther Acevedo (1995, p. 162) lo recupera en el contexto más amplio sobre cómo "el uso de la fotografía amenazó el poder de la litografía".

${ }^{20} \mathrm{Y}$ con la sentencia de que se trataba de un viaje de aventuras, desprovisto de interés para la ciencia. F. de Waldeck. Les antiquités mexicaines et la photographie. Le Trait D'Union, 19 de abril de 1862, pp. 3-4. Otros autores señalan que Charnay no estuvo solamente 24 horas, sino nueve días en Palenque (Bittencourt y Carrillo, 2014, p. 121). 


\section{REFLEXIONES FINALES}

Para cerrar este texto que analiza lo escrito por Désiré Charnay, resulta interesante recuperar una acusación que hizo este autor para justificar los problemas en sus registros fotográficos en Palenque. En su texto más conocido dice que uno de las dificultades para realizar sus fotografías se debió a que los indios "no quisieron de ningún modo limpiar las hierbas que cubrían el friso de la fachada, tampoco cortar los árboles que estorbaban y que escondían la mayor parte de los detalles. Tenían miedo, decían, de ver el edificio derrumbarse bajo sus pies" (Charnay, 1994, p. 222). Si al Estado mexicano no le interesó preservar los vestigios arqueológicos o no quería incomodar a los exploradores con reclamos, es importante revalorar que Charnay y otros viajeros similares tuvieron un freno en los pobladores locales, incluso cuando estos eran presionados por las autoridades.

Existen evidencias de que ciertos sectores de las poblaciones por las que Charnay cruzó o en las que se asentó a la fuerza, no compartían sus puntos de vista ni objetivos. En Mitla, al observar que algunas elevaciones del terreno podrían ser tumbas llenas de "ricos tesoros científicos", escribió que se esforzó "por realizar algunas búsquedas, pero en vano; los indios no permiten tocar los viejos recuerdos de sus ancestros. Hubiera necesitado el apoyo del gobierno, el cual la agitación y la amenaza de un sitio me impidieron obtener." En otra ocasión señala que existe una actitud beligerante de los indios que vigilan "que ninguna mano profana ataque" restos de su pasado. Charnay define esta actitud, "como a todo lo que concierne a su pasado", de "una supersticiosa veneración". Y señala que en su objetivo de "extraer los tesoros que encierran" algunos sitios, requería del apoyo que no puede "obtener de un gobierno desorganizado que no podía sostenerse a sí mismo". En ese sentido se puede decir que, lo que Charnay calificó de "actitud hostil de los indios" (Charnay, 1994, pp. 117, 121 y 125), fue lo que permitió la preservación de parte del patrimonio arqueológico.

Sin embargo, estas y otras actitudes de los locales fueron calificadas por el explorador como la miseria moral de los mexicanos, y dado que publicó Ciudades y ruinas americanas cuando la intervención militar francesa contra nuestro país ya estaba en marcha, el explorador exclamó sin tapujos: "México sólo puede aplaudir el éxito y el desarrollo de la expedición francesa" (Charnay, 1994, p. 89). Esto porque en su narración los únicos que parecen ser bene- 
ficiarios de su respeto o consideración son los sabios y estudiosos con nobles intereses en su trabajo de exploración y descubrimientos.

La invisibilización, la reproducción de los comentarios racistas y la naturalización de la humillación de las personas por quienes se sentían superiores, sean estas las elites mexicanas o los exploradores, ha sido parte de la construcción de las ciencias sociales. Por eso resulta paradigmática la imagen de Charnay "Pasaje de la cordillera" (véase imagen 1), ya que entre los que han analizado el trabajo de Désiré Charnay, pocos han comentado directamente la imagen o la justificación que dio el explorador para montar a un semejante. ${ }^{21}$

En todo caso se ha ponderado el discurso de las molestias que sufrió Charnay, el sentimiento desagradable donde se mezcla un "profundo disgusto por la humillación que se impone a un ser de la misma naturaleza que uno y que lo lleva, por así decirlo, sobre su lomo". Con todo, el explorador estuvo listo para justificar el uso de la montura, porque era "un medio de locomoción muy usado en la montaña y que no posee ningún atractivo", y a que, a final de cuentas, para él, "el desdichado tiene tan poca conciencia de su degradación, que uno termina por acostumbrarse" (Charnay, 1994, p. 251). Para evitar "acostumbrarnos" a las imágenes de dominio y explotación de personas, se propone esta imagen de "Paisaje de la cordillera" como la representación más adecuada de Désiré de Charnay y una forma de reflexionar cómo se hacía la investigación de lo social en buena parte del siglo XIx.

El uso de la fotografía como parte de las investigaciones arqueológicas se planteó desde la presentación del daguerrotipo en 1839 y en los años siguientes se hicieron registros empleando distintos procesos de manufactura en diferentes partes del mundo. En el caso de México, el barón Emmanuel von Friedrichsthal realizó los primeros daguerrotipos de la zona maya en 1840 y tres años después John Lloyd Stephens y Frederick Catherwood llevaron una cámara de daguerrotipos durante su segundo viaje (Casanova y Debroise, 1989, pp. 24-25; Taracena y Sellen, 2006). Es muy probable que entre esas primeras exploraciones y los registros que realizó Pál Rosti de Xochicalco en 1857, se hayan producido otras indagaciones que usaron la fotografía como parte de sus trabajos de registro, nuevas investigaciones son necesarias para rescatar estos procesos e imágenes.

${ }^{21}$ Davies (1981, pp. 182-183). Para uno de los biógrafos de Charnay, la imagen le remite únicamente a una idea que se puede desarrollar dentro de lo que denomina un sendero iconográfico. Es decir, una imagen (Mongne, 2009, pp. 193, 198 y 265). 
En ese contexto, Charnay no fue propiamente un pionero; sin embargo, hasta el momento ha sido publicitado por difusores de temas culturales (no académicos) como si este personaje no solamente fuera un héroe de las exploraciones arqueológicas, sino el iniciador de la fotografía en este campo en todo el mundo (Gómez, 2014; Grupo Salinas, 2018; Reyna, 2018). Charnay no fue el primero en hacer este tipo de registros, no hizo su trabajo fotográfico en solitario, no utilizó una técnica diferente a la empleada en la época y existe la hipótesis razonable de que su trabajo buscó emular el realizado por Pál Rosti. Quedan varios pendientes, entre ellos, realizar un análisis de los procesos de manufactura usados en las fotografías de Charnay y Rosti. Pero para avanzar es pertinente romper con la idea que hemos venido cultivando acerca de las labores de los exploradores y fotógrafos del pasado.

En el caso de Charnay, a pesar de que no hemos querido verlo, las evidencias del trabajo colaborativo están ahí presentes, por ello es necesario recuperar la información sobre los viajeros decimonónicos que realizaron diversas actividades en México, por ejemplo, poniendo atención no solamente en los "beneficios" que aportaron, sino también en el patrimonio que se llevaron a sus lugares de origen. Puede suceder que la información sea menos cuantiosa o que se encubran esos datos, o que deliberadamente no se quiera poner atención a esos temas incómodos para no empañar el buen nombre de grandes personajes que, se piensa, hicieron tanto por la cultura en México. Dichos personajes se cobraron por adelantado los supuestos servicios prestados. Viajaban muchas veces con recursos de sus gobiernos, desarrollaban sus actividades con protección del gobierno mexicano y sus representantes locales, se aprovechaban del trabajo, explotaban física y económicamente a la población local, se llevaban piezas históricas y las vendían a buen precio. $\mathrm{Y}$, a pesar de ello, es impresionante que estos relatos casi épicos sigan siendo atractivos como historias de sufridos personajes, de héroes desinteresados en la creación de imágenes en beneficio de la humanidad.

\section{LISTA DE REFERENCIAS}

Acevedo, E. (1995). El legado artístico de un imperio efímero. Maximiliano en México, 1864-1867. En Testimonios artísticos de un episodio fugaz, 1864-1867 (pp. 33-193). México: Museo Nacional de Arte/Patronato del Museo Nacional de Arte/Instituto Nacional de Bellas Artes. 
Bernal, I. (1992). Historia de la arqueología en México. México: Editorial Porrúa.

Bittencourt, J. y Carrillo, P. (2014). A través del lente del explorador: una aproximación al álbum fotográfico Ciudades y ruinas americanas, de Désiré Charnay. Boletín de Monumentos Históricos, tercera época (31), 116-131.

Casanova, R. (2005). De vistas y retratos: la construcción de un repertorio fotográfico en México, 1839-1890. En Imaginarios y fotografía en México 1839-1970 (pp. 3-57). Barcelona: ConAculta/INAH/Lunwerg.

Casanova, R. y Debroise, O. (1989). Sobre la superficie bruñida de un espejo. México: Fondo de Cultura Económica.

Catherwood, F. (1978). Visión del mundo maya 1844. México: Cartón y Papel de México.

Charnay, D. (1884). Mis descubrimientos en México y en la América Central. En América pintoresca: descripción de viajes al nuevo continente por los más modernos exploradores. Carlos Wiener, doctor Crevaux, D. Charnay, etc., etc. (pp. 275-476) Barcelona: Montaner y Simon.

Charnay, D. (1885). Les Anciennes Villes du Nouveau Monde, Voyages d'Explorations au Mexique et dans l'Amérique Centrale. 1857-1882. París: Hachette.

Charnay, D. (1978). Viaje a Yucatán a fines de 1886. México: Fondo Editorial de Yucatán.

Charnay, D. (1994). Ciudades y ruinas americanas: Mitla, Palenque, Izamal, Chichén Itzá, Uxmal. México: Dirección General de Publicaciones-ConAculta.

Davis, K. (1981). Désiré Charnay, expeditionary photographer. Albuquerque: University of New Mexico.

Debroise, O. (1989). Claude Désiré Charnay. México: Consejo Nacional para la Cultura y las Artes/Instituto Nacional de Bellas Artes/Centro Cultural Santo Domingo.

Debroise, O. (1994). Fuga mexicana. México: Conaculta.

Esmeraldo, S. (2007). Techniques photographiques de Désiré Charnay: les negatifs au collodion. En Le Yucatán est ailleurs, expéditions phothographiques (1857-1886) de Désiré Charnay (pp. 86-88). París: Musée du quai Branly-Actes Sud.

Farcy, C. (1927). Discurso preliminar histórico. 1834. Anales del Museo Nacional de Arqueología, Historia y Etnografía, v(119), 485-498.

Gallegos, J. (1999). Dos visitas a México, ¿un solo país? La mirada en dos libros de Charnay. En Los pueblos indios y el parteaguas de la independencia de México (pp. 269316). México: Instituto de Investigaciones Jurídicas-UNAM.

Gómez, J. (2014). Las vírgenes de Charnay. Forasterongt. Recuperado de https://forasterongt.wordpress.com/2014/07/03/colodion-charnay/

Grupo Salinas (2018). Claude Désiré Charnay. Arte \& Cultura. Recuperado de http:// www.arteyculturags.org/2018/04/14/claude-desire-charnay-2/ 
Jancsó, K. (2013). Húngaros en los trópicos. Rosti Pál y otros viajeros en el Caribe y en América Central en la segunda parte del siglo xIX. En Acta hispánica XVIII (pp. 73-82). Szeged: Departamento de Estudios Hispánicos-Universidad de Szeged.

Jazzán-Dayán, S. (2017). La mirada artística de la modernidad. Alfred Briquet en México. En G. Leroy y S. Jazzán-Dayán. Alfred Briquet 1833-1926 (pp. 14-73). México: Museo Nacional de Arte.

Los grandes fotógrafos (17 de marzo de 2017). Claude-Joseph Désiré Charnay (1828-1915). [Blog spot]. Recuperado de http://losgrandesfotografos.blogspot. mx/2017/03/claude-joseph-desire-charnay-1828-1915.html

Martínez, J. (2019). Las mestizas yucatecas en la obra de Désiré Charnay: 1860-1882. En Fotógrafos extranjeros, mujeres mexicanas. En proceso.

Mongne, P. (2001). Désiré Charnay: Explorateur, archéologue, photographe et écrivain. En D. Charnay, Voyage au Mexique 1858-1861 (pp. 13-55). París: Ginkgo Éditeur.

Mongne, P. (2009). El sendero iconográfico. La imagen de las Américas popularizada: dos ejemplos mesoamericanos. En F. Pino-Díaz, P. Riviale y J. Villarías-Robles (eds.) Entre textos e imágenes. Representaciones antropológicas de la América indígena (pp. 193-199). Madrid: Consejo Superior de Investigaciones Científicas.

Ochoa, L. (1994). Prólogo. Pasajes amargos. En D. Charnay. Ciudades y ruinas americanas: Mitla, Palenque, Izamal, Chichén Itzá, Uxmal (pp. 11-27). México: Dirección General de Publicaciones-Conaculta.

Odena, L. (1988). La fotografía. En C. García y M. Valle (coords.), La antropología en México. Panorama histórico. T. 6. (pp. 611-634). México: INAH (Colección Biblioteca del INAH).

Pedro Robles, A. E. de (2009). Viajeros, selva, ciudades pérdidas e ídolos feos. Antigüedades americanas en el pensamiento americanista europeo del siglo xIx. Indiana, 26, 209-232. DoI: http://dx.doi.org/10.18441/ind.v26i0.209-232

Podgorny, I. (2008). Antigüedades portátiles: transportes, ruinas y comunicaciones en la arqueología del siglo xIx. História, Ciências, Saúde - Manguinhos, 15(3), 577-595.

Rau, Ch. (1882). Tablero del Palenque en el Museo Nacional de los Estados Unidos. Anales del Museo Nacional de México, II(2), 131-203.

Reyna, C. (24 de octubre de 2018). Désiré Charnay: incansable explorador. Gatopardo. Recuperado de https:/gatopardo.com/cultura/desire-charnay/

Rodríguez, J. (2007). Ciudades y ruinas americanas: la versión nacional. Alquimia, 31, 22-23.

Scharf, A. (2001). Arte y fotografía. Madrid: Alianza Editorial. 
Schávelzon, D. (2003). La Comisión Científica Francesa a México (1864-1867) y el inicio de la arqueología en América. Pacarina, Arqueología y Etnografía Americana, año III(3), 313-322.

Taft, R. (1964). Photography and the American scene: A social history, 1839-1889. Nueva York: Dover Publications.

Taracena, A. y Sellen, A. (2006). Emanuel von Friedrichsthal: su viaje a América y el debate sobre el origen de la civilización maya. Península, I(2), 49-67.

Valverde, F. (2012). Désiré Charnay: vista panorámica de la Ciudad de México. Alquimia, 44, 83-85.

\section{OTRAS FUENTES}

\section{Archivos}

Archivo Fotográfico Manuel Toussaint del Instituto de Investigaciones Estéticas-Universidad Nacional Autónoma de México, México.

Fototeca Nacional, SinAfo-Instituto Nacional de Antropología e Historia, México.

Fundación Cultural Televisa, México.

Mapoteca Manuel Orozco y Berra, Secretaría de Agricultura, Ganadería, Desarrollo Rural, Pesca y Alimentación, México. 